\title{
HORIZONTES AMAZÔNICOS: PARA REPENSAR O BRASIL E O MUNDO [BRUNO MALHEIRO, CARLOS WALTER PORTO-GONÇALVES, FERNANDO MICHELOTTI]
}

\author{
DOI: http://10.9771/gmed.v13i2.45996
}

\author{
Joaquina Barata Teixeira ${ }^{1}$
}

Título: Horizontes amazônicos: para repensar o Brasil e o mundo Autoras/es: Bruno Malheiro, Carlos Walter Porto-Gonçalves, Fernando Michelotti Editora: São Paulo: Expressão popular

Ano da publicação: 2021

Páginas: 300

A presente obra, iniciativa da Fundação Rosa Luxemburgo e da Editora Expressão Popular (no bojo da Coleção Emergências), é uma ousada, magnífica e original iniciativa de elaboração de conteúdos não colonizados sobre a Amazônia e seus povos, região cujos longos anos de história e vivência são reconhecidamente de grande relevância "para os destinos da vida no planeta" (p. 13).

Trata-se de uma pesquisa que não fratura o horizonte social segundo a divisão do trabalho das pesquisas científicas no âmbito das instituições acadêmicas, mas agrega as dimensões da totalidade social das relações sociais concretas na análise da realidade.

A obra condensa o registro de um estudo que entra forte no campo de nosso interesse pela Amazônia e seus povos originários, interesse acentuado desde que, em uma equipe interdisciplinar, tivemos contato com várias etnias indígenas na área do Alto Rio Negro e Uaupés - estado do Amazonas fronteira com a Colômbia. O tema invadiu a alma da equipe, agigantou-se, virou paixão, mas ressentiu-se da ausência ou escassez de referências e estudos identificados com a região e seus povos, o que felizmente encontramos nesta obra.

É lembrada, no conteúdo desta obra resenhada, a forte e inadequada influência da colonialidade constitutiva do capitalismo, que transformou, ao longo dos séculos, esta rica região "em um espaço vazio e atrasado" "de natureza inóspita" (p.15), e que hoje, ainda sob a referência de um mercado alienado, cuja riqueza é acumulada pela apropriação do valor trabalho, recusa-se a dialogar com o grande acervo de conhecimentos (patrimônio acumulado em 13.000 anos de história) das diversas etnias e povos da região, que oferecem sim, ao mundo, outros horizontes teóricos e outros "saberes/sabores de seus povos" (p. 18).

Registre-se quatro abordagens ao tema nesta magnífica obra que o mundo precisa encarar: 1) a identificação de uma “ofensiva espoliadora” (p. 20) no avanço sobre a Amazônia, exigindo uma rigorosa 
crítica da economia política que a obra faz muito bem;2) a atualização da dinâmica espoliadora enfrentada pelos povos amazônicos no seio das relações de poder e governo dos territórios; 3) o desenvolvimento de formulações de uma ecologia política crítica, identificando que a lógica capitalista na Amazônia impõe, sim, um "colapso metabólico" ao planeta (p. 20); 4) a quarta abordagem, no seio de uma ontologia política, indica que há sim outros modos de ser e produzir vida na Amazônia, o que seus povos já faziam há milênios, o que exige uma ruptura com o modelo da exportação de commodities presente na região como via generalizada de um pretenso desenvolvimento. A obra finaliza dialogando com o legado teórico e político dos povos amazônicos, na busca de outros horizontes para a vida no planeta.

Estão registradas, na obra, as recentes queimadas destrutivas da floreta amazônica, as pilhagens e os desmatamentos promovidos por fazendeiros, madeireiros e empresários, sob o consentimento e patrocínio do, pasmem, Ministério do Meio Ambiente, sob as ordens de um Presidente da República de extrema direita: conservador, sectário, racista, homofóbico, inculto, genocida e patriarcal, a serviço do aumento da apropriação privada da terra e de suas riquezas.

O texto atualiza as formas brutais do avanço do capitalismo na Amazônia, o acirramento das disputas pelo acesso e domínio do território e recursos da região, as prioridades dadas à produção e exportação de commodities por parte de um Estado anacrônico e antidemocrático, e de uma burguesia que ainda pratica um capitalismo em que coexistem amplos territórios de latifúndio, trabalho escravo, trabalho servil e trabalho assalariado, todos demasiadamente explorados. Não é de espantar, portanto, a imensidão da pobreza e extrema-pobreza no Brasil.

Esta magnífica pesquisa identifica, na colonização das Américas e seus povos, assimetrias e hierarquizações que precisam fazer parte dos estudos de uma ecologia política crítica, capaz de apontar um colapso metabólico na Amazônia, com consequências dramáticas para todo o planeta. Como identificam os pesquisadores, a não realização da reforma agrária no Brasil alimentou e acentuou a invasão da Amazônia por formas inadequadas de estradas que se distanciaram dos rios, rasgando e desmatando sobre florestas e ferrovias a serviço do capital, sob a referência do famigerado conceito colonial de desenvolvimento que, conforme os autores, sobrepôs-se aos anteriores e também ideológicos conceitos de "catequizar, colonizar e civilizar" (p. 156).

Como demonstram os autores, a noção de "desenvolvimento" que fundamenta o discurso ideológico contemporâneo e a cobiça pela Amazônia, presente no bojo do atual avanço destrutivo do capital, integram, contemporaneamente, as investidas da globalização, do neoliberalismo e da pósmodernidade

Informações novas e recentes, contidas na obra destes autores, dão conta de que as terras férteis da Amazônia, a exemplo a "valorizada terra preta" (p. 205), resultam da prática observada, estudada e redefinida pela ação humana dos povos que habitaram a região. A ciência colonialista jamais teve esse insight, como identificam os autores deste trabalho. Além das manchas de terra preta, mencionam os pesquisadores o que Juliana Lins lista com certa propriedade, uma série de elementos na paisagem amazônica, "como montículos artificiais, florestas antrópicas como os castanhais e babaçuais, geoglifos 
etc.” (p. 206), reforçando que as sociedades originárias da Amazônia eram muito mais contributivas e inventivas com o planeta do que o modo de produção capitalista dominante na terra, Mas o mais importante para a autora, é que esses legados, como o da terra preta e as áreas com elevada diversidade florestal, mantêm-se até os dias atuais e são altamente relevantes para os sistemas de produção e diversificados manejos dos povos e comunidades do campo na Amazônia atual, configurando-se como uma das bases para a agroecologia na região.

Outras pesquisas, acessadas pelos pesquisadores, mapearem a riqueza da diversidade biológica da Amazônia, registrando que as áreas de maior diversidade são aquelas com a presença dos povos tradicionais. Os autores identificam que várias espécies tidas como nativas da Amazônia são resultado de verdadeiros "cultivadores locais", como são os casos da pupunha e do Ouricuri e como nativas eu acrescentaria a andiroba, com seu largo espectro de solução para casos de dores musculares na região.

Apontam os autores da pesquisa as concentrações anormais para os padrões da floresta amazônica de algumas espécies nativas, em algumas áreas, como os castanhais no Pará ou no Acre, indicativos da "floresta antrópica", ou melhor, da "floresta tropical cultural úmida" (POSEY e BALÉE, 1989; POSEY, 1987).

$\mathrm{Na}$ Amazônia é comum encontrar-se, como referem os autores, "uma diversidade biológica maior do que em todas as florestas das regiões de clima temperado e frio dos países do Hemisfério Norte” (p. 209). E, também, como referem os autores, é comum que várias espécies não se repitam no hectare vizinho.

Referem com muita propriedade os autores que o mundo da floresta tropical se distancia enormemente da monocultura, aí ser uma violência simbólica e material reflorestar com plantio homogêneos de árvores, como fazem os fazendeiros na Amazônia e no mundo, com o dendê, o eucalipto e o pinus. Recordam ainda os autores que muitas das plantas que hoje nos alimentam foram domesticadas pelos povos da Amazônia, a exemplo a mandioca, as amêndoas, a castanha-do-pará, o guaraná, valendo mencionar também as plantas medicinais como a ipecacuanha, a copaíba, a quinina, até plantas de uso industrial, como a borracha, a palmeira de carnaúba, o timbó etc. Ou seja, os povos originários são também produtores de biodiversidade e não se pode mais ignorar a contribuição desses povos não só na criação de diversidade biológica ou biocultural, como também o seu papel para que esse imenso legado chegasse até nós.

Entre os pesquisadores e intelectuais brasileiros acessados pela pesquisa, cabe destacar a importância de José Veríssimo (1857-1916), paraense de Óbidos, que chamara a atenção para o profundo sentido de liberdade dos amazônidas, pela cultura que haviam desenvolvido com a floresta, sobretudo por saberem desfrutar da sua enorme produtividade biológica primária que lhes garantia frutos comestíveis, tratamento para suas doenças, material para sua arquitetura e alimento os mais variados.

Não obstante toda essa riqueza e vida em profusão, percebe-se e os autores identificam, uma investida espoliadora contra a Amazônia e seus povos, praticadas por latifundiários, banqueiros e o próprio Estado. 
A obra finaliza com nove fortes afirmações necessárias, em coerência com os seus conteúdos, aqui resumidas, a saber: 1) povos amazônicos oferecem ao mundo uma outra gramática/práxis que tem na complementaridade e reciprocidade das sociedades e naturezas sua força vital; 2) Mais que direitos humanos, fale-se em direito à vida, humana e não-humana; 3) ao invés de progresso, modernização e desenvolvimento, precisamos falar em vida em plenitude; 4) ao invés de soberania ligada ao Estado e à existência de um povo no singular, fale-se em plurinacionalidade, com o reconhecimento jurídico de múltiplas nações indígenas convivendo no Estado; 5) restitua-se ao conceito de democracia o seu sentido pleno, como governo do povo, pelo povo e para o povo; 6) rompamos com o conceito de propriedade privada da terra, que significa privação das condições metabólicas de reprodução da vida (solo-terrasubsolo-água-fauna/flora/fotossíntese); 7) mais do que se falar em biotecnologia para uma economia do conhecimento sustentável comandada por interesses de grandes corporações mundiais, fale-se em reconhecimento da autonomia das territorialidades e territórios dos grupos/povos/classes que trabalham; 8) não se deve continuar a nutrir a amnésia biocultural que advém unicamente da exportação de commodities como o único caminho na Amazônia. É necessário que pensemos, a agroecologia como uma via não apenas de soberania alimentar do campo e da cidade, mas como modo de restituir a memória biocultural dos povos amazônicos; 8) rompamos com a ilusão do desenvolvimentismo e da mercantilização das terras e da natureza, ouvindo os povos amazônicos em busca de agroecologia, soberania alimentar e dignidade; 9) não apenas antagonizar com forças capitalistas que invadem territórios amazônicos, mas afirmar formas distintas de usar a terra, a floresta, os rios, os mares, as várzeas, os campos, as terras firmes e as distintas territorialidades!

Esta resenha finaliza homenageando os seus autores, que conseguiram abrir ao Brasil e ao mundo verdades há muito sufocadas sobre a Amazônia e seus povos.

\footnotetext{
Notas

1 Professora aposentada da Universidade Federal do Pará (UFPA). Integrante do Grupo de Pesquisa Política Urbana e Movimentos Sociais na Amazônia globalizada - http://dgp.cnpq.br/dgp/espelhogrupo/269765. Currículo Lattes: http://lattes.cnpq.br/1819868033745261. Orcid: https://orcid.org/0000-0003-1420-8016. E-mail: joaquina@,ufpa.br.
} 